\title{
INHIBITION OF BIOFILM PRODUCING GRAM NEGATIVE CLINICAL ISOLATES AND THEIR ANTIBIOGRAM PATTERN
}

\author{
Ojaswee Shrestha ${ }^{1}$, Nabina Shrestha ${ }^{1}$, Sadhana Khanal ${ }^{1}$, Sushant Pokhrel $^{1}$, Sujina \\ Maharjan $^{1}$, Tika Bdr Thapa ${ }^{1}$, Puspa Raj Khanal ${ }^{2}$, and Govardhan Joshi ${ }^{1}$ \\ ${ }^{1}$ Manmohan Memorial Institute of Health Sciences \\ ${ }^{2}$ Sumeru Hospital Pvt. Ltd.
}

February 23, 2021

\begin{abstract}
Background: Bacterial biofilm is a major virulence factor that posses a threat to patients leading to chronic infections. Therefore, it is crucial to identify biofilm production as well as their inhibition and reduction. This study was an attempt to investigate biofilm production among gram-negative isolates and assessment of inhibitory and reduction potential of EDTA and DMSO towards them and also observe the antimicrobial resistance pattern among biofilm producers and biofilm non-producer. Methods: Isolation and identification of bacterial isolates were performed by standard microbiological methodology. The antibiotic susceptibility pattern was determined by the Kirby Bauer disk diffusion method and $\beta$-lactamases by the combination disk method. Biofilm formation was detected through Tissue Culture Plate(TCP) method, and different concentrations of EDTA and DMSO were used to determine their inhibitory and reduction property against biofilm. Both inhibition and reduction by the various concentration of EDTA and DMSO were analyzed using paired t-test. Results: Among the 110 clinical isolates $61.8 \%$ were found to be Multidrug resistance(MDR) with the $33(30 \%)$ produced Extended-spectrum $\beta$-lactamases(ESBL), 16 (14.5\%)Metalloß-lactamases(MBL) and 9 (8\%)Klebsiella pneumonia carbapenemase(KPC). Biofilm formation was detected in $35.4 \%$ of isolates. Biofilm producing organisms showed antibiotics resistance to Cephalosporins, Chloramphenicol, Gentamycin, and Carbapenem. The inhibition and reduction of biofilm were significantly lower $(\mathrm{p}<0.05)$ for $1 \mathrm{mM}$ of EDTA and $2 \%$ of DMSO. Conclusions: EDTA and DMSO were found to possess potential activity against biofilm. Hence, EDTA and DMSO might be used invitro as an effective antibiofilm agent to control the biofilm-associated infection and for a possible therapeutic approach.
\end{abstract}

\section{Hosted file}

Manuscript final biofilm.pdf available at https://authorea.com/users/397499/articles/510360inhibition-of-biofilm-producing-gram-negative-clinical-isolates-and-their-antibiogrampattern

\section{Hosted file}

tables biofilm.pdf available at https://authorea.com/users/397499/articles/510360-inhibitionof-biofilm-producing-gram-negative-clinical-isolates-and-their-antibiogram-pattern

\section{Hosted file}

Figures biofilm.pdf available at https://authorea.com/users/397499/articles/510360inhibition-of-biofilm-producing-gram-negative-clinical-isolates-and-their-antibiogrampattern 